\title{
Xenon-iodine dating: Primordial xenon in meteorites
}

\author{
P. K. KURODA \\ Department of Chemistry, University of Arkansas \\ Fayetteville, Arkansas, 72701 U.S.A.
}

(Received May 4, 1976)

\begin{abstract}
The difference in the xenon-iodine formation intervals for the magnetite samples from the carbonaceous chondrites Orgueil, Murchison and Karoonda is less than 0.7 million years and the chondrites Bjurböle and Arapahoe began to retain xenon a few million years after the magnetites. The isotopic composition of the trapped xenon in these meteorites is identical to that of the carbonaceous chondrite Murray.
\end{abstract}

\section{INTRODUCTION}

LEWIS and ANDERS (1975) have recently made the important discovery that two magnetite samples from the carbonaceous chondrites Orgueil (C1) and Murchison (C2) are older than any other material dated thus far by extinct 16 million year ${ }^{129} \mathrm{I}$ and concluded that their age provide a suitable zero point for the chronology of the solar system.

DROZD and PODOSEK (1976), however, reported that the xenon-iodine formation age of the chondrite Arapahoe (L5) is the oldest yet observed, and hence it is unlikely that younger ages found in carbonaceous chondrite magnetite record the condensation of the solar nebula. Moreover, they reported that the composition of trapped xenon in Arapahoe is such that there must have been a large deficiency of ${ }^{129} \mathrm{Xe}$ in a region of the solar system at the time of its formation.

It was felt that the conflicting views expressed by these investigators may have resulted from the fact that the experimental data were not properly interpreted, and hence we have decided to re-examine the data obtained by the above-mentioned investigators. A brief summary of the results is presented in this report.

\section{RESUlTS AND Discussion}

Figure 1 shows the Orgueil, Murchison and Karoonda data obtained by LEWIS and ANDERS (1975). The straight-lines $a$ and $b$ in Fig. 1 have the same slopes as the high-temperature correlation lines drawn for Murchison and Karo- onda, respectively, in Fig. 2 of the paper by LEWIS and ANDERS (1975). It is interesting to note that the straightline $a$ passes through the point $P$ representing the isotopic composition of the xenon in the non-irradiated carbonaceous chondrite Murray (KuRoda et al., 1974), but the straightline $b$ does not. Thus, the isotopic composition of the trapped xenon in Karoonda must be different from that of the xenon in Murray. There is no easy way, however, to find the isotopic composition of the trapped xenon in Karoonda. We only know that it should fall on the line $b$, but if it is represented by a point such as $P^{\prime}$ in Fig. 1 , the ${ }^{130} \mathrm{Xe} /{ }^{129} \mathrm{Xe}$ ratio is normal, but the ${ }^{128} \mathrm{Xe} /{ }^{129} \mathrm{Xe}$ ratio is almost zero. If, on the other hand, it is represented by $P^{\prime \prime}$ in Fig. 1 , the ${ }^{128} \mathrm{Xe} /{ }^{129} \mathrm{Xe}$ ratio is normal, but the ${ }^{130} \mathrm{Xe} /{ }^{129} \mathrm{Xe}$ ratio is much smaller than that of Murray. It may be located at an intersection $\left(P^{\prime \prime \prime}\right)$ of the straightline $b$ and the line connecting zero and the point $P$. If that is the case, the ${ }^{128} \mathrm{Xe} /{ }^{130} \mathrm{Xe}$ ratio is the same as that in Murray, but the ${ }^{129} \mathrm{Xe} /{ }^{130} \mathrm{Xe}$ is much greater than that in Murray.

Figure 2 shows the Arapahoe and Bjurbole data obtained by DROzD and PoDoseK (1976). Note that we have plotted here not only the data points for all the xenon fractions released from these meteorites, but also the isotopic compositions of the xenon, which are retained by the meteorites at each released temprature. The data points for high temperature xenon fractions from Bjurböle fall on a straightline $a b$, which passes through the Murray point $P$ in Fig. 2. The straightline $a^{\prime} b^{\prime}$ in Fig. 2, on which 


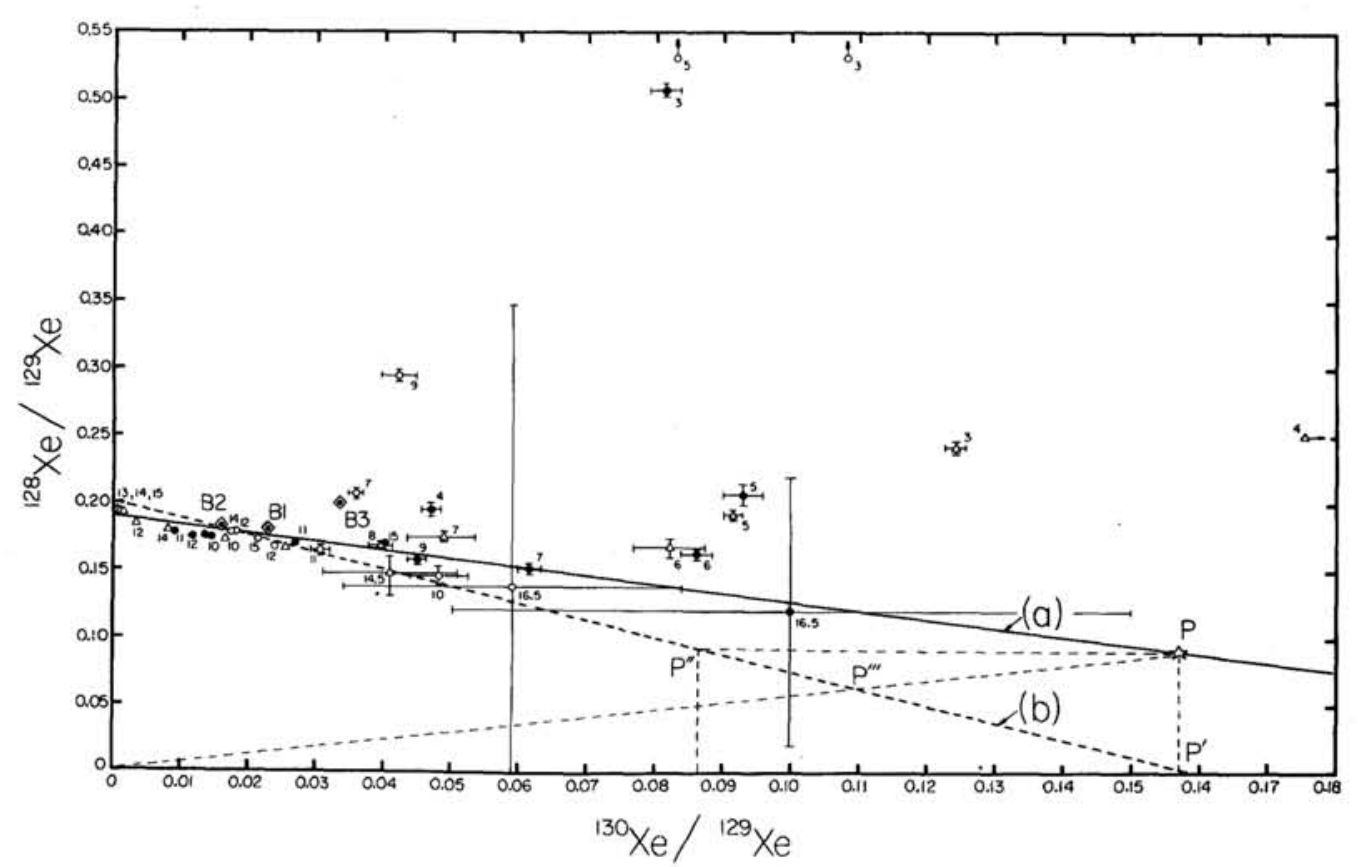

Fig. 1. Correlation plot for ${ }^{128} \mathrm{Xe} /{ }^{129} \mathrm{Xe}$ versus ${ }^{130} \mathrm{Xe} /{ }^{129} \mathrm{Xe}$ of the xenon released from pile-irradiated magnetite samples of Orgueil, Murchison and Karoonda in stepwise heating experiments (LEWIS and ANDERS, 1975). $B 1=$ Orgueil magnetite bulk; $B 2=$ Murchison magnetite bulk; $B 3=$ Karoonda magnetite bulk; $P=$ Murray bulk; $P^{\prime}, P^{\prime \prime}$ and $P^{\prime \prime \prime}=$ assumed isotopic compositions for the trapped xenon in Karoonda; $\bullet$ Orgueil; $\triangle$ Murchison; - Karoonda; the data points are labeled by release temperature in hundreds of ${ }^{\circ} \mathrm{C}$. The straightline a has the same slope as the straightline drawn for the Murchison data points and the dotted line $b$ has the same slope as the line drawn for Karoonda sample in Fig. 2 of LEWIS and ANDERS (1975).

the high temperature Arapahoe data points fall, however, has a quite different slope and it does not pass through the Murray point $P$.

DROzD and PoDOSEK (1976) have considered the possibility that the isotopic composition of the trapped xenon in Arapahoe might be represented by the point $P^{\prime}$ or $P^{\prime \prime}$ in Fig. 2 . If it is $P^{\prime}$, the ${ }^{128} \mathrm{Xe} /{ }^{132} \mathrm{Xe}$ ratio in the trapped component is the same as that of Murray, while the ${ }^{129} \mathrm{Xe} /{ }^{132} \mathrm{Xe}$ ratio is abnormally low. If, on the other hand, the trapped component is represented by $P^{\prime \prime}$, the ${ }^{129} \mathrm{Xe} /{ }^{132} \mathrm{Xe}$ ratio is normal, but the ${ }^{128} \mathrm{Xe} /{ }^{132} \mathrm{Xe}$ ratio is about 5 times the value of Murray. By rejecting the latter possibility as being absurd, DROZD and PODOSEK (1976) have concluded that the abundance of ${ }^{129} \mathrm{Xe}$ in the trapped xenon in Arapahoe must be abnormally low as shown by the point $P^{\prime}$ in Fig. 2.

If we are to accept the conclusion reached by DROzD and PoDoseK (1976) that ${ }^{129} \mathrm{Xe} /{ }^{132} \mathrm{Xe}$ $=0.56$ in the trapped component of Arapahoe, we are forced to conclude that ${ }^{129} \mathrm{Xe} /{ }^{130} \mathrm{Xe}=$ $1 / 0.11=9.1$ for the trapped component of Karoonda, as shown by the point $P^{\prime \prime}$ in Fig. 1 .
This corresponds to ${ }^{129} \mathrm{Xe} /{ }^{132} \mathrm{Xe}=1.48$, which is about 43 percent higher than the value of 1.032 for Murray. If the difference in the xenon-iodine formation ages of Arapahoe and Karoonda is only a few million years, it is difficult to explain such a large difference in the abundance of ${ }^{129} \mathrm{Xe}$ in the trapped xenon in these meteorites.

These difficulties encountered in interpreting the xenon isotope data strongly suggest the possibility that the problem lies in the principle of the xenon-iodine dating method itself. According to the universally accepted theory of the xenon-iodine dating method (FISH and Goles, 1962; ReYNolds, 1963), the following relationship should hold:

$$
\frac{{ }^{129} \mathrm{Xe}}{{ }^{132} \mathrm{Xe}}=\left(\frac{{ }^{129} \mathrm{Xe}}{{ }^{132} \mathrm{Xe}}\right)_{\mathrm{A}}+K \cdot\left(\frac{{ }^{128^{*} \mathrm{Xe}}}{{ }^{132} \mathrm{Xe}}\right)
$$

where

$$
K=\left(\frac{{ }^{129 *} \mathrm{Xe}}{{ }^{127} \mathrm{I}}\right) \cdot\left(\frac{{ }^{127} \mathrm{I}}{{ }^{128^{*} \mathrm{Xe}}}\right)
$$




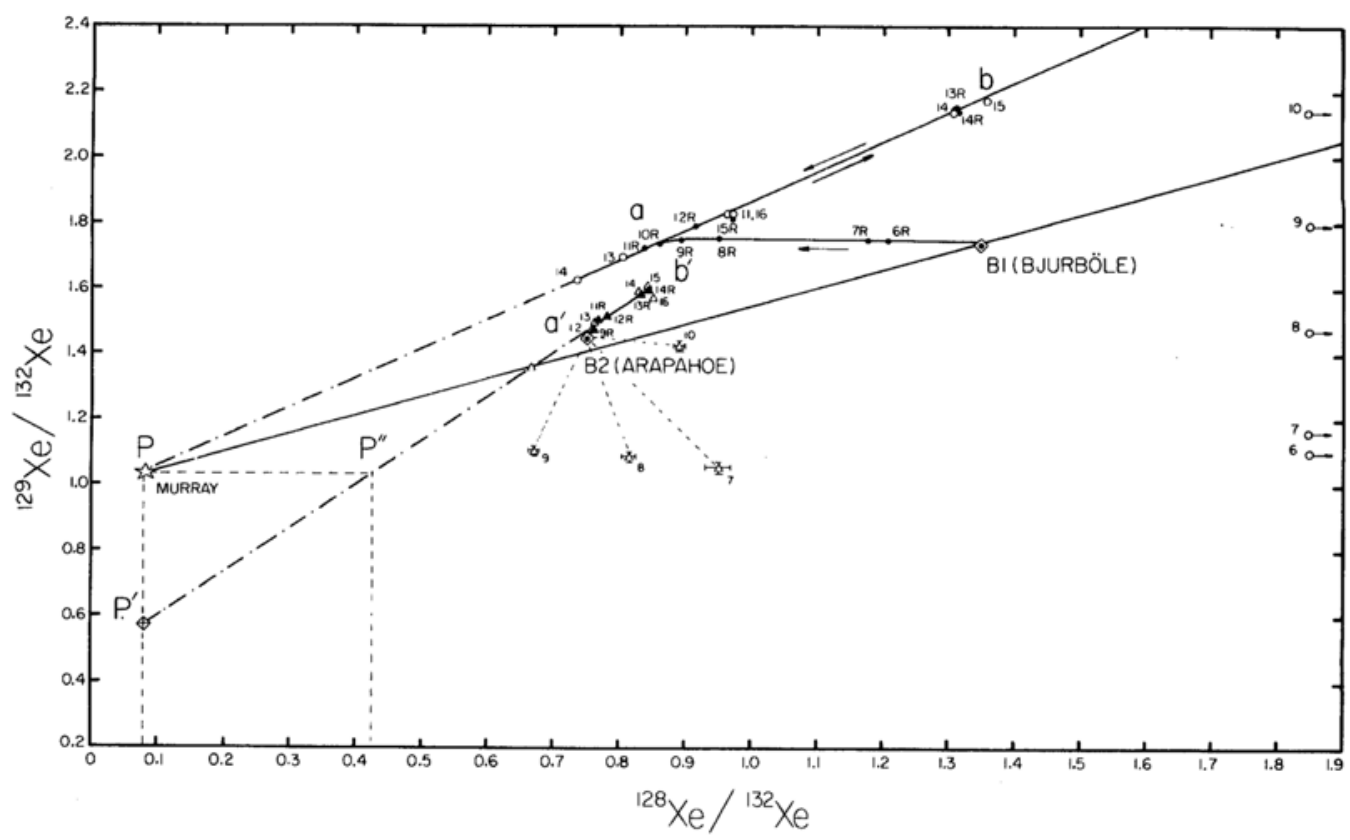

Fig. 2. Correlation plot for ${ }^{129} \mathrm{Xe} /{ }^{132} \mathrm{Xe}$ versus ${ }^{128} \mathrm{Xe} /{ }^{132} \mathrm{Xe}$ of the xenon released from and retained by the pile-irradiated Bjurböle and Arapahoe chondrites during stepwise heating experiments (DROZD and PODOSEK, 1976). B1 = Bjurböle bulk; B2 = Arapahoe bulk; $\bigcirc$ xenon released from Bjurböle; $\bullet$ xenon retained by Bjurböle; $\triangle$ xenon released from Arapahoe; $\mathbf{\Delta}$ xenon retained by Arapahoe; $P=$ Murray bulk; $P^{\prime}$ and $P^{\prime \prime}=$ assumed isotopic ratios for the trapped xenon in Arapahoe. The data points are labeled by release temperature in hundreds of ${ }^{\circ} \mathrm{C}$.

and ${ }^{129 *} \mathrm{Xe}$ and ${ }^{128 *} \mathrm{Xe}$ refer to the radiogenic ${ }^{129} \mathrm{Xe}$ from the decay of ${ }^{129} \mathrm{I}$ and ${ }^{128} \mathrm{Xe}$ from the neutron-capture reactions on ${ }^{127} \mathrm{I}$.

Thus, if the experimental data are plotted on a ${ }^{129} \mathrm{Xe} /{ }^{132} \mathrm{Xe}$ versus ${ }^{128 *} \mathrm{Xe} /{ }^{132} \mathrm{Xe}$ diagram, the points should fall on a straightline, and its slope gives $K$. The intercept of the straightline gives the ambient $\left({ }^{129} \mathrm{Xe} /{ }^{132} \mathrm{Xe}\right)_{\mathrm{A}}$ ratio for the specimen, a quantity which the method determines, unlike gross $\mathrm{Xe}$ analysis in which this method has to be assumed in order to calculate an I-Xe age. It seems to the present author, however, that the method does not necessarily determine the ambient $\left({ }^{129} \mathrm{Xe} /\right.$ $\left.{ }^{132} \mathrm{Xe}\right)_{\mathrm{A}}$ ratio, because the meteorites are complex aggregates of many minerals and hence the xenon released from minerals with different formation intervals may affect the slope of the straightline.

Let us for the sake of simplicity consider the case in which the meteorite consists of two kinds of minerals ( 1 and 2 ) with different formation intervals. The isotopic composition $\left(R^{\mathrm{i}}\right)$ of the xenon released from the mineral 1 may then be considered as mixtures of trapped xenon $\left(P^{\mathrm{i}}\right)_{\mathrm{A}}$ and the xenon $\left(Q^{\mathrm{i}}\right)_{1}$ released from a region of the mineral, where the concentrations of ${ }^{129 *} \mathrm{Xe}$ and ${ }^{127} \mathrm{I}$ are the highest, in the ratio of $1-\alpha$ and $\alpha$ :

$$
R^{\mathrm{i}}=\left(P^{\mathrm{i}}\right)_{\mathrm{A}} \cdot(1-\alpha)+\left(Q^{\mathrm{i}}\right)_{1} \cdot \alpha
$$

where $R^{\mathrm{i}}, P^{\mathrm{i}}$ and $Q^{\mathrm{i}}$ are the ${ }^{\mathrm{i}} \mathrm{Xe} /{ }^{132} \mathrm{Xe}$ ratios and $\mathrm{i}=128$ and 129 .

A similar relationship should hold for the xenon released from the mineral 2 and hence the isotopic composition of the xenon released from the two minerals may be given by the equation

$$
\begin{aligned}
R^{\mathrm{i}}= & \left\{\left(P^{\mathrm{i}}\right)_{\mathrm{A}} \cdot(1-\alpha)+\left(Q^{\mathrm{i}}\right)_{1} \cdot \alpha\right\} \cdot \gamma+ \\
& \left\{\left(P^{\mathrm{i}}\right)_{\mathrm{A}} \cdot(1-\beta)+\left(Q^{\mathrm{i}}\right)_{2} \cdot \beta\right\} \cdot(1-\gamma)
\end{aligned}
$$

where the subscripts 1 and 2 refer to the minerals 1 and 2 and $0 \leqq \alpha, \beta, \gamma \leqq 1$.

Equation (4) contains three variables, $\alpha, \beta$, $\gamma$, and hence it appears as if the observed data points are not likely to fall on a single straightline if the values of $R^{129}$ are plotted against the values of $R^{128}$. This appears to be the case when the melting points of the minerals 1 and 2 are rather low - say, below $1,000^{\circ} \mathrm{C}$.

If the melting points of the minerals are higher than $1,000^{\circ} \mathrm{C}$, however, the situation may be quite different. By the time the release tem- 
perature reaches the point just below the melting points - of the minerals, the values of both $\alpha$ and $\beta$ may approach 1 and Equation (4) may take the form

$$
R^{\mathrm{i}} \cong\left(Q^{\mathrm{i}}\right)_{1} \cdot \gamma+\left(Q^{\mathrm{i}}\right)_{2} \cdot(1-\gamma)
$$

and hence the observed data points may fall on a straightline representing a mixing line between the isotopic ratios $\left(Q^{\mathrm{i}}\right)_{1}$ and $\left(Q^{\mathrm{i}}\right)_{2}$ for the minerals 1 and 2 , respectively. The slope of the straightline is

$$
\frac{R^{129}}{R^{128}}=\frac{\left(Q^{129}\right)_{2}-\left(Q^{129}\right)_{1}}{\left(Q^{128}\right)_{2}-\left(Q^{128}\right)_{1}}
$$

and it will not pass through the point representing the isotopic ratio $\left(P^{129} / P^{128}\right)_{\mathrm{A}}$ of the trapped component, as it is illustrated schematically in Fig. 3.

Let us now return to the Bjurböle and Arapahoe data shown in Fig. 2. Because of the fact that the xenon fractions, in which the ${ }^{128} \mathrm{Xe} /{ }^{132} \mathrm{Xe}$ ratios are extremely high, are released from Bjurböle at low temperatures, the isotopic composition of the xenon remaining in the meteorite changes to the left as shown by an arrow and reaches the point $a$ in Fig. 2. The data points for the xenon fractions released and for those retained by the meteorite at temperatures near $1,000^{\circ} \mathrm{C}$ cluster around $a$, sug-

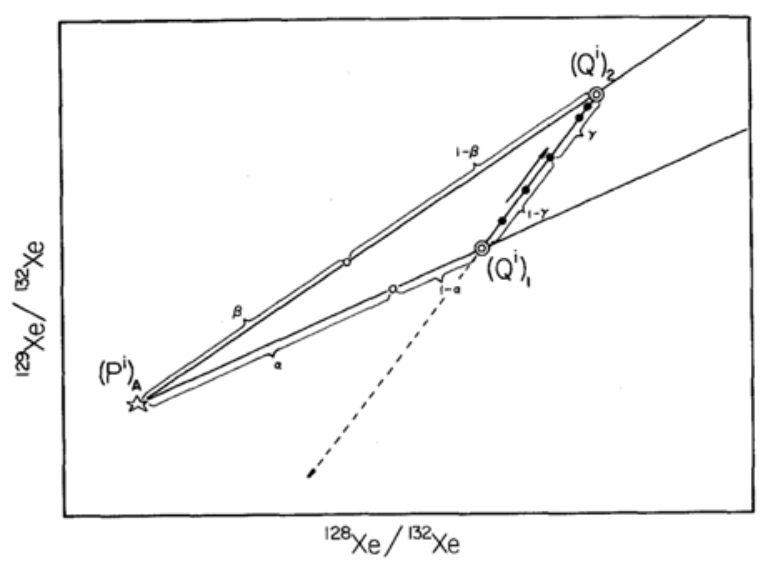

Fig. 3. Correlation plot for ${ }^{129} \mathrm{Xe} /{ }^{132} \mathrm{Xe}$ versus ${ }^{128} \mathrm{Xe} /$ ${ }^{132} \mathrm{Xe}$ illustrating the relationship between the isotopic compositions of the ambient xenon $\left(P^{i}\right)_{A}$ and the xenon in two groups of minerals with different xenon-iodine formation intervals: $\left(Q^{i}\right)_{1}$ and $\left(Q^{i}\right)_{2}$. gesting that minerals with the melting points of about $1,000^{\circ} \mathrm{C}$ may be releasing the bulk of the xenon at this point. As the temperature is raised above $1,200^{\circ} \mathrm{C}$, the isotopic composition of the xenon still remaining in the meteorite shifts to the point indicated by $b$ in Fig. 2 .

A similar, though less spectacular, trend is observed for the chondrite Arapahoe. The isotopic composition of the xenon remaining in the meteorite gradually shifts from $a^{\prime}$ to $b^{\prime}$ as the temperature is raised from about $1,000^{\circ} \mathrm{C}$ to $1,600^{\circ} \mathrm{C}$ and a straightline can be drawn through the observed data points as shown by the line $a^{\prime} b^{\prime}$ in Fig. 2. The line $a^{\prime} b^{\prime}$ can be extrapolated to $P^{\prime}$, which corresponds to the isotopic composition of the trapped xenon as postulated by DROzD and PODOSEK (1976).

The line $a b$ can be extrapolated to the Murray point as shown in Fig. 2. This is most likely due to the fact that the initial ${ }^{129} \mathrm{I} /{ }^{127} \mathrm{I}$ ratio, when the minerals with the melting points of approximately $1,000^{\circ} \mathrm{C}$ began to retain xenon, was almost identical to that of the second group of minerals, whose melting points are in the 1,300 to $1,500^{\circ} \mathrm{C}$ range as indicated by the points $a$ and $b$, respectively, in Fig. 2 .

The points $a^{\prime}$ and $b^{\prime}$ in Fig. 2 correspond to the values of ${ }^{129 *} \mathrm{Xe} /{ }^{128 *} \mathrm{Xe}=0.657$ and 0.745 , respectively. These values correspond to a difference of the initial ${ }^{129} \mathrm{I} /{ }^{127} \mathrm{I}$ ratio amounting to 11.8 percent or a ${ }^{129} \mathrm{I}-{ }^{129} \mathrm{Xe}$ decay interval of $2.8 \mathrm{M}$. yr. Thus the fact that the high temperature data points for Arapahoe fall on the line $a^{\prime} b^{\prime}$ can be explained as due to the fact that we are dealing here with mixtures of xenon fractions released by minerals belonging to two groups, one group of minerals having a melting point of about $1,000^{\circ} \mathrm{C}$ and another about 1,300 to $1,500^{\circ} \mathrm{C}$, and the initial ${ }^{129} \mathrm{I} /{ }^{127} \mathrm{I}$ ratios in these minerals were different from each other.

Let us now turn our attention to the magnetite data obtained by LEwIS and ANDERS (1975). If the ${ }^{128} \mathrm{Xe} /{ }^{129} \mathrm{Xe}$ ratio is plotted against the ${ }^{130} \mathrm{Xe} /{ }^{129} \mathrm{Xe}$ ratio, as it was done by these investigators, a plot such as shown in Fig. 1 emerges and we encounter a great difficulty in accurately drawing the so-called correlation lines. We have therefore re-normaliced their data to ${ }^{130} \mathrm{Xe}$. Figures 4,5 and 6 show the Orgueil, Murchison and Karoonda magnetite data. The data points for not only the xenon fractions released, but also for the xenon retained by the meteorites at each release temperature are plotted here. The Murchison magnetite data 


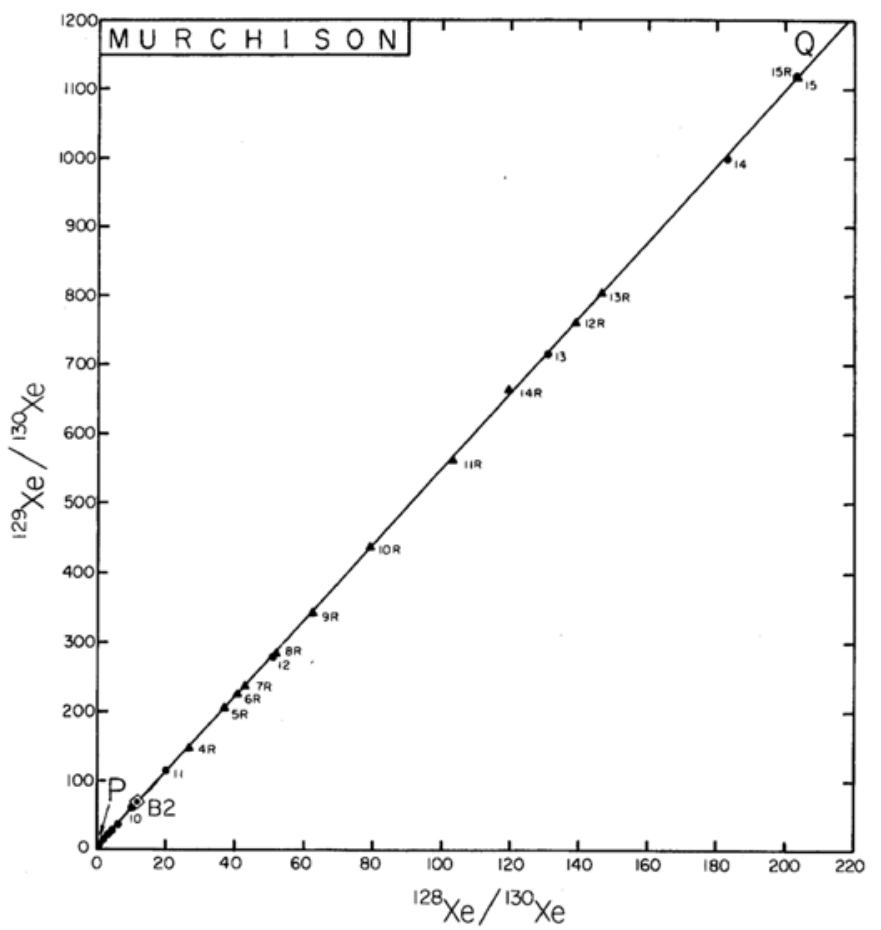

Fig. 4

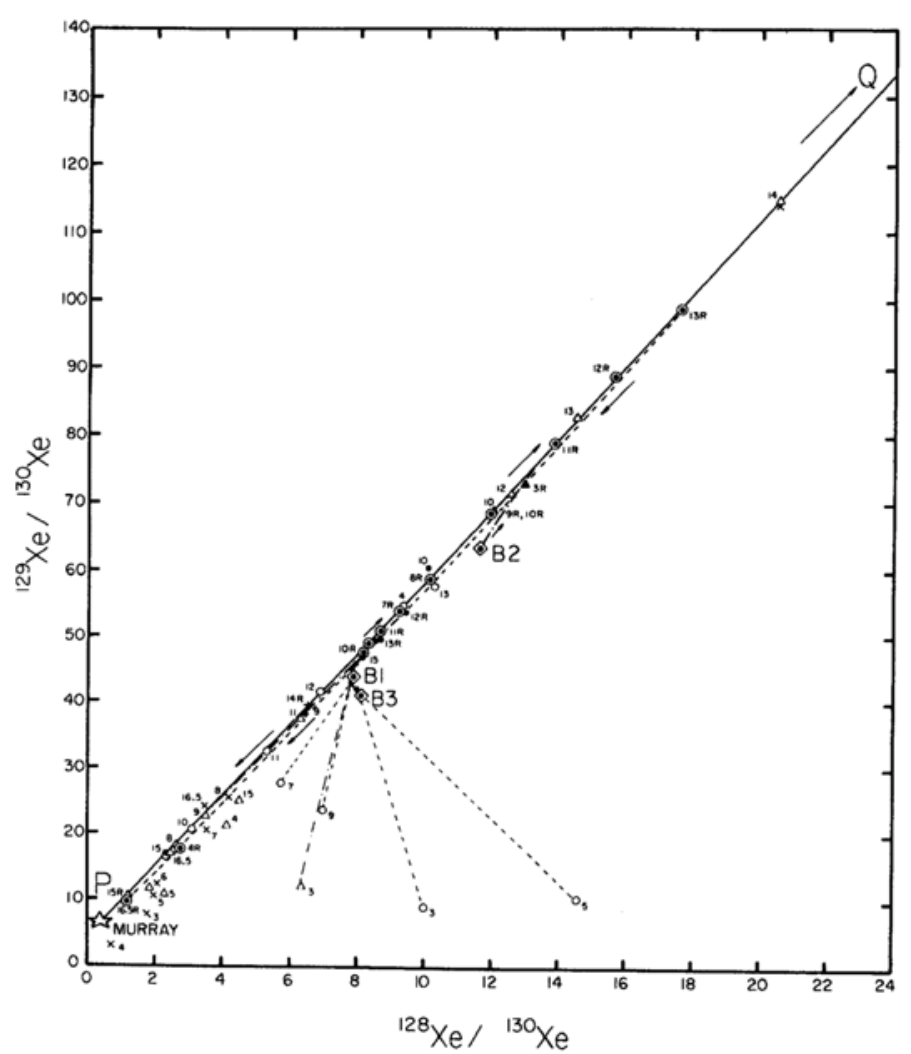

Fig. 5
Fig. 4. Correlation plot for ${ }^{129} \mathrm{Xe} /{ }^{130} \mathrm{Xe}$ of the xenon released from and retained by the pile-irradiated Murchison magnetite during stepwise heating experiments. $\quad$ B2 $=$ Murchison magnetite bulk; - xenon released; $\Delta$ xenon retained; the data points are labeled by release temperature in hundreds of ${ }^{\circ} \mathrm{C}$.

Fig. 5. Correlation plot for ${ }^{129} \mathrm{Xe} /{ }^{130} \mathrm{Xe}$ versus ${ }^{128} \mathrm{Xe} /{ }^{130} \mathrm{Xe}$ of the xenon released from and retained by the pile-irradiated magnetites from Orgueil, Murchison and Karoonda during stepwise heating experiments. $\quad B 1=$ Orgueil magnetite bulk; $B 2$ $=$ Murchison magnetite bulk; $B 3=$ Karoonda magnetite bulk; $\triangle$ xenon released from Orgueil; $\odot$ xenon retained by Orgueil; $X$ xenon released by Murchison; $\wedge$ xenon retained by Murchison; 0 xenon released Karoonda; - xenon retainèd by Karoonda; the data points are labeled by release temperature in hundreds of ${ }^{\circ} \mathrm{C}$. 


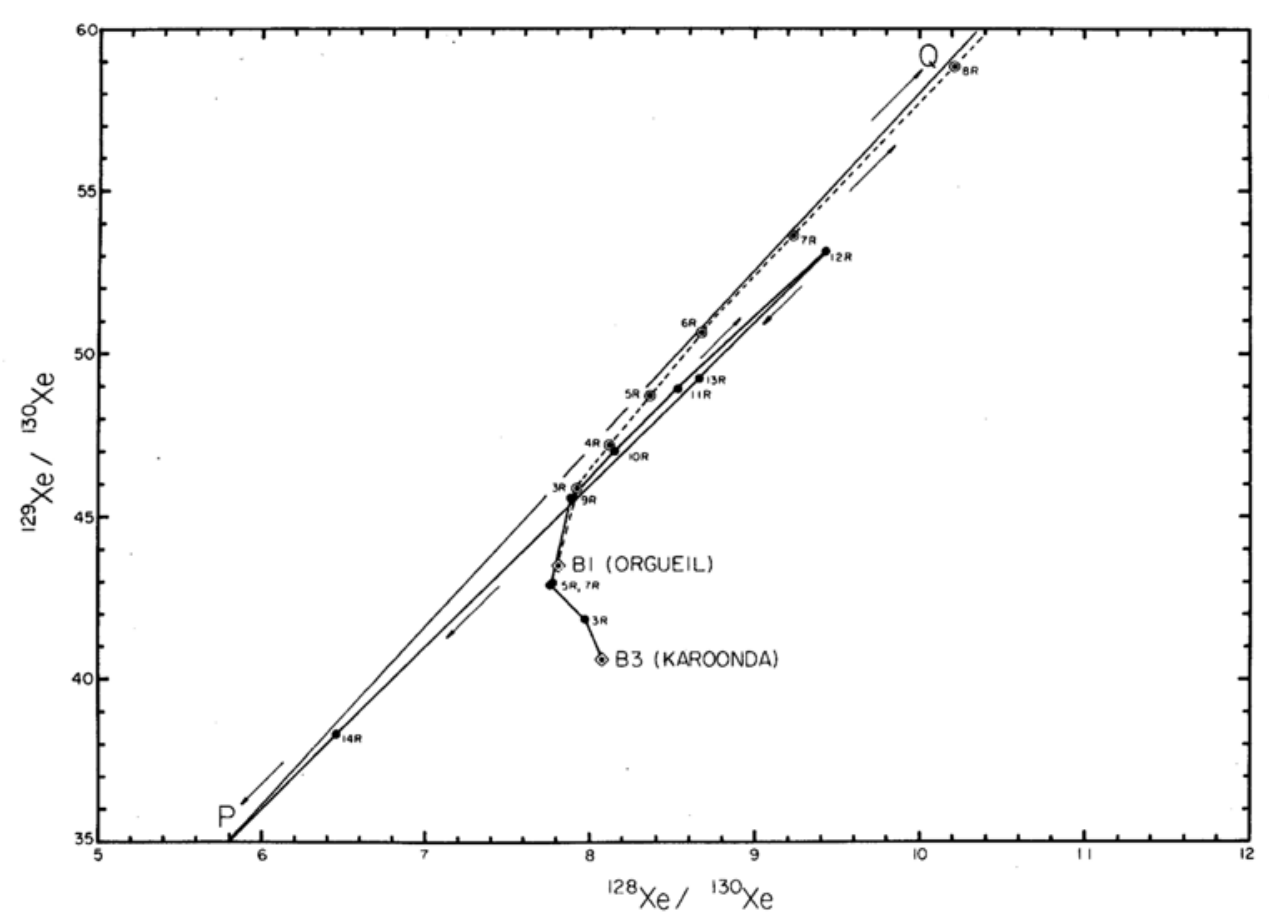

Fig. 6. Correlation plot for ${ }^{129} \mathrm{Xe} /{ }^{130} \mathrm{Xe}$ versus ${ }^{128} \mathrm{Xe} /{ }^{130} \mathrm{Xe}$ illustrating the change of the isotopic compositions of the xenon retained by the pile-irradiated Orgueil and Karoonda magnetites with release temperature. The notations are the same as in Fig. 5.

points define a beautiful straightline $P Q$ passing through the Murray point, as shown in Fig. 4. The Orgueil and Karoonda magnetite data points are plotted on an enlarged scale in Fig. 5. The line $P Q$ in Fig. 5 represents the straightline defined by the Murchison data and the high temperature data points for the Orgueil and Karoonda magnetites fall on this line. The deviations of the high temperature data points from the straightline $P Q$ are such that the data indicate that these minerals were formed within a time period of less than one million years. Figure 6 shows the isotopic compositions of the xenon remaining in the Karoonda and Orgueil magnetites at each release temperature on a greatly expanded scale. The difference in the slope of the straightline defined by the Karoonda data points and that of the Murchison line $(P Q)$ seems to be real and it corresponds to a difference in the initial ${ }^{129} \mathrm{I} /{ }^{127} \mathrm{I}$ ratios amounting to approximately 3 percent, which is equivalent to a difference in the ${ }^{129} \mathrm{I}-{ }^{129} \mathrm{Xe}$ time interval of only 0.7 million years. The real difference in the time of formation of the magnetites from Karoonda, Murchison and Orgueil may be even smaller than this. According to LEWIS and ANDERS (1975), the Karoonda sample showed strong lines of olivine, in addi- tion to those of magnetite, and they estimated that olivine comprised at least one half of the sample. If so, a somewhat different pattern of variation of the xenon isotope ratios observed for Karoonda may very well be due to the effect caused by minerals other than magnetite.

Acknowledgment-This investigation was supported by the National Science Foundation under Grant NSF EAR 76-00285.

\section{REFERENCES}

D ROZD, R. J., and PoDoseK, F. A. (1976) Primordial ${ }^{129} \mathrm{Xe}$ in meteorites. Earth Planet. Sci. Lett. (in press).

FiSH, R. A., and Goles, G. G. (1962) Ambient xenon: a key to the history of meteorites. Nature 196, 27-31.

KURODA, P. K., BECK, J. N., EFURD, D. W. and MILlER, D. K. (1974) Xenon isotope anomalies in the carbonaceous chondrite Murray. J. Geophys. Res. 79, 3981-3992.

LEWIS, R. S., and ANDERS, E. (1975) Condensation time of the solar nebula from extinct ${ }^{129} \mathrm{I}$ in primitive meteorites, Proc. Nat. Acad. Sci. USA. 72, 268273.

REYNOLDS, J. H. (1963) Xenology. J. Geophys. Res. 68, 2939-2956. 